\title{
Anisocoric pupil generated by azygos anterior cerebral artery: a case report
}

\author{
WICHMANN, J. F. ${ }^{1}$, GOULART, G. R. ${ }^{1}$, XAVIER, L. L. ${ }^{2}$, JOTZ, G. P. ${ }^{3}$, \\ MALYSZ, T. ${ }^{3}$, BORBA JUNIOR, A. M. ${ }^{1}$ and CAMPOS, D. ${ }^{1,4 *}$
}

\author{
${ }^{1}$ Departamento de Biologia e Farmácia, Universidade de Santa Cruz do Sul - UNISC, Avenida Independência, \\ 2293, CEP 96815-900, Santa Cruz do Sul, RS, Brazil \\ ${ }^{2}$ Laboratório de Biologia Celular e Tecidual, Departamento de Ciências Morfofisiológicas, \\ Faculdade de Biociências, Pontifícia Universidade Católica do Rio Grande do Sul - PUC-RS, \\ Avenida Ipiranga, 6681, CEP 90610-000, Porto Alegre, RS, Brazil \\ ${ }^{3}$ Departamento de Ciências Morfológicas, Instituto de Ciências Básicas da Saúde, Universidade Federal do Rio \\ Grande do Sul - UFRGS, Avenida Sarmento Leite, 500, CEP 90050-170, Porto Alegre, RS, Brazil \\ ${ }^{4}$ Departamento de Ciências Básicas da Saúde, Universidade Federal de Ciências da Saúde de Porto \\ Alegre - UFCSPA, Avenida Sarmento Leite, 245, CEP 90050-170, Porto Alegre, RS, Brazil \\ *E-mail: dcampos@ufcspa.edu.br
}

\begin{abstract}
Introduction: In the embryonic period, several developmental anomalies of the cerebral arteries occur. The knowledge of these anatomic variations is important to avoid unnecessary surgery and to undergo surgery or interventional radiology with safety. Objective: In this report, we discuss the hypothesis of the presence of azygos anterior cerebral artery as a possible cause of anisocoric pupil found in a patient with 35 years old. To our knowledge, this variation has not been previously reported. Results: In this study we reported a case of this artery emphasizing some morphological, functional and clinical data about this rare vascular abnormality. Conclusion: The results could be important to offer useful information to anatomists, radiologists, ophthalmologists, neurologists and head and neck surgeons.
\end{abstract}

Keywords: angiography, azygos anterior cerebral artery, anisocoric pupil.

\section{Introduction}

At times in clinical neurology, the identification of a subtle clinical or radiological sign can lead to prompt diagnosis of a very rare or difficult case (PORTO, SILVA, DOMINGUES et al., 2012). In the context, an azygos anterior cerebral artery (AACA) is an uncommon to rare variant seen in approximately $0.4-1 \%$ of the population in which the two segments of the anterior cerebral artery (ACA) join to form a single midline trunk that supplies blood to both hemispheres (HUH, PARK, SHIN et al., 2007).

The AACA is frequently associated with other malformations of the central nervous system, such as porencephalic cysts, agenesis of the corpus callosum, hydranencephaly, and saccular aneurysms (HUH, PARK, SHIN et al., 2007). Among them, the incidence of aneurysms is about $13-71 \%$. There are two generally accepted mechanisms for the formation of such aneurysms: the aneurysms develop alongside a congenital anomalous artery, or the aneurysms result from hemodynamic stress caused by the AACA (KANEMOTO, TANAKA, NONAKA et al., 2000).

However, although some studies have provided important information about the circle of Willis (EFTEKHAR, DADMEHR, ANSARI et al., 2006; SUEMOTO, GRINBERG, APARECIDA et al., 2008), ACA (STEFANI, SCHNEIDER, MARRONE et al., 2000; TUBBS, SHOJA, SHOKOUHI et al., 2007) and AACA (WAN-YIN, MING-HUA, BIN-XIAN et al., 2014), little is known about other neurological disorders caused by the AACA, especially if it can cause some ocular alteration. Thereby, the aim of this report is to demonstrate by computed tomography angiography (CTA) examinations the presence of AACA as a possible cause of anisocoric pupil. This hypothesis presented is based on evidence from a case report.

\section{Case Report}

A 35-year-old woman was evaluated in 2013-2016 due to anisocoric pupil, her left has greater diameter than right $(\mathrm{L}>\mathrm{R})$ (Figure 1). The right pupil was normal; although the left pupil was constantly mydriatic, the pupillary reflex was normal bilaterally with the proportional increase of their diameter in accord to the ambient light conditions. The movement of both ocular globes was absolutely normal, with absence of ptosis, hemifacial anhidrosis and enophtalmia. The patient had no history of any loss of consciousness or and seizures. Also there was no previous medical history or family history of hypertension or diabetes mellitus. At the time of clinical evaluation the patient was in good health, lucid, and coherent, arterial blood pressure of $120 / 90 \mathrm{mmHg}$. No cognitive deficits. Moreover, the force and movement were preserved in all members. The functions of the cranial nerves were preserved and there was no change in deep and superficial reflections. CTA of the head showed the presence of AACA without the presence of saccular aneurysm (Figure 2). 


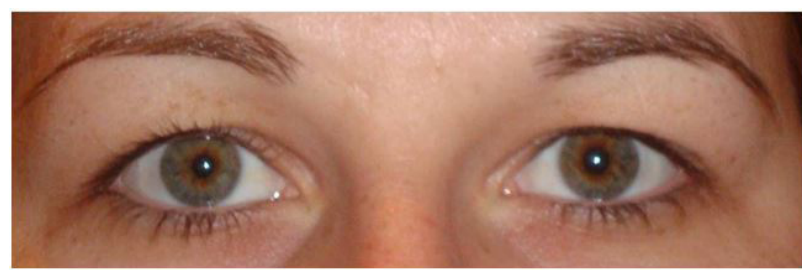

Figure 1. Image showing the anisocoric pupil in the patient. Note that left pupil is larger when compared to the right pupil, in the same light conditions.

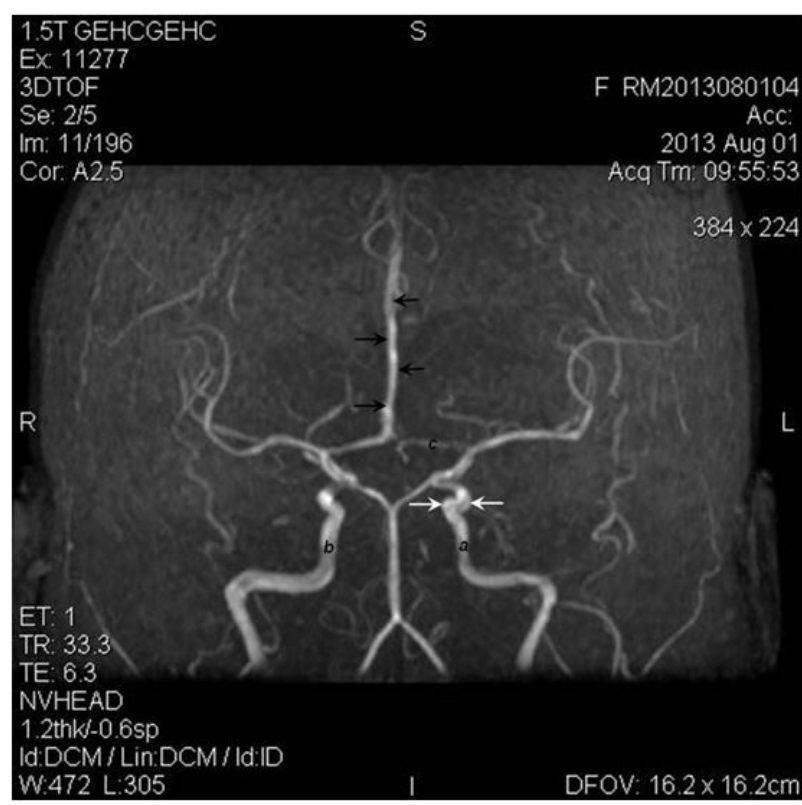

Figure 2. Cerebral angiography with contrast demonstrating the presence of azygos anterior cerebral artery [black arrow]. Angiography also demonstrates that the distal portion of the left internal carotid artery (a) [white arrow] is larger than the distal part of the right internal carotid artery (b). Hypoplasia of the left anterior communicating artery $(\mathrm{c})$.

\section{Discussion}

From Figure 2, it appears clearly that there is a slight dilatation of the distal portion of the left internal carotid artery and a hypoplasia of the left anterior communicating artery that could contribute to the elevation of the pressure of the cavernous sinus, which will result in the compression of the oculomotor nerve. Therefore, it is possible to draw a parallel between the presence of this rare anatomical variation (AACA) and occurrence of pupillary anisocoria described in our report.

This hypothesis is based on the fact that the presence of AACA inevitably increases the volume of blood in the internal carotid arteries. Thus, probably in one of the internal carotid arteries larger volume of blood accumulates, thereby increasing the pressure in the cavernous sinus, which allows the passage of the oculomotor nerve. Therefore, in this case, the oculomotor nerve compression produced by AACA was responsible for the left mydriasis observed. This can be easily seen on brain scan (Figure 2), which showed the distal portion of the left internal carotid artery larger than the same portion of the right carotid artery. This slight dilation of the left internal carotid artery can cause a small left oculomotor nerve compression and thus explain the pupil dilation of the patient's left eye (Figure 1) due functional component of the pupil of the left oculomotor nerve.

This can be proved by the fact that in chronic compressive lesions of the distal carotid aneurysm, the pupil is almost always affected by dilation or reduced light response (LEE and BRAZIS, 2003). According to previous descriptions (CAMPOS, MASSARO and SCAFF, 2003), pupillary involvement is not a rule, but in some cases mydriasis may be the only manifestation for the few days preceding the complete oculomotor nerve palsy. In other patients the pupil tends to be miotic, presumably because of the concurrent oculosympathetic palsy due to the pericarotid sympathetic plexus involvement.

Approximately half of patients with aneurysms in the cavernous sinus have an abnormality in the oculomotor nerve (LINSKEY, SEKHAR, HIRSCH JUNIOR et al., 1990). In addition, peripherally located fibers mediating pupillary constriction (parasympathetic supply to the eye) (MOORE, DALLEY and AGUR, 2011), are first injured during compression within the cavernous sinus, thus generating progressive dilation of the pupil on the injured side as first symptom of a compressive disorder. The other oculomotor nerve fibers which control the extraocular muscles are still preserved in the patient due their inner localization; therefore, these functions have not yet been affected. This may explain the slight mydriasis observed in our patient.

\section{Conclusion}

In conclusion, this study highlights the relationship between the AACA and anisocoria (anisocoric pupil) which has not been previously described in the current literature, making the need to pay attention to the recognition of this variation and its various manifestations. Structural imaging of nervous system has undergone many technical enhancements that have made possible to explain more signs and symptoms previously assumed to be "normal variant".

\section{References}

CAMPOS, CR., MASSARO, AR. and SCAFF, M. Isolated oculomotor nerve palsy in spontaneous internal carotid artery dissection: case report. Arquivos de Neuro-Psiquiatria, 2003, vol. 61, n. 3A, p. 668-670. PMid:14513178. http://dx.doi.org/10.1590/S0004282X2003000400027.

EFTEKHAR, B., DADMEHR, M., ANSARI, S., GHODSI, M., NAZPARVAR, B. and KETABCHI, E. Are the distributions of variations of circle of Willis different in different populations? Results of an anatomical study and review of literature. BMC Neurology, 2006, vol. 6, n. 1, p. 22. PMid:16796761. http://dx.doi.org/10.1186/14712377-6-22.

HUH, JS., PARK, SK., SHIN, JJ. and KIM, TH. Saccular aneurysm of the azygos anterior cerebral artery: three case reports. Journal of Korean Neurosurgical Society, 2007, vol. 42, n. 4, p. 342-345. PMid:19096567. http://dx.doi.org/10.3340/jkns.2007.42.4.342.

KANEMOTO, Y., TANAKA, Y., NONAKA, M. and HIRONAKA, Y. Giant aneurysm of the azygos anterior cerebral artery-case report. Neurologia Medico-Chirurgica, 2000, vol. 40, n. 9, p. 472-475. PMid:11021080. http://dx.doi.org/10.2176/nmc.40.472. 
WICHMANN, J. F., GOULART, G. R., XAVIER, L. L. et al.

LEE, AG. and BRAZIS, PW. Clinical pathways in neuro-ophthalmology: an evidence based approach. 2nd ed. New York: Thieme Medical Publishers, 2003.

LINSKEY, ME., SEKHAR, LN., HIRSCH JUNIOR, WJR., YONAS, $\mathrm{H}$. and HORTON, JA. Aneurysms of the intracavernous carotid artery: clinical presentation, radiographic features, and pathogenesis. Neurosurgery, 1990, vol. 26, n. 1, p. 71-79. PMid:2294481. http:// dx.doi.org/10.1227/00006123-199001000-00010.

MOORE, KL., DALLEY, AF. and AGUR, AMR. Anatomia orientada para a clínica. 6. ed. Rio de Janeiro: Guanabara Koogan, 2011.

PORTO, FH., SILVA, MN., DOMINGUES, JR., PORTO, GC., DAVAGNAMAN, I. and NITRINI, R. The missed missing hole. Arquivos de Neuro-Psiquiatria, 2012, vol. 70, n. 6, p. 467-469. PMid:22699546. http://dx.doi.org/10.1590/S0004-282X2012000600015.

STEFANI, MA., SCHNEIDER, FL., MARRONE, AC., SEVERINO, AG., JACKOWSKI, AP. and WALLACE, MC. Anatomic variations of anterior cerebral artery cortical branches. Clinical Anatomy (New York, N.Y.), 2000, vol. 13, n. 4, p. 231-236. PMid:10873213. http://dx.doi. org/10.1002/1098-2353(2000)13:4<231::AID-CAl>3.0.CO;2-T.
SUEMOTO, CK., GRINBERG, LT., APARECIDA, MSS., JACOB FILHO, W. and PASQUALUCCI, CA. Anatomical variations of circle of Willis in an autopsy study in the city of São Paulo. Journal of Morphological Science, 2008, vol. 25, p. 157-214.

TUBBS, RS., SHOJA, MM., SHOKOUHI, G., ASHRAFIAN, F. and OAKES, WJ. Unusual origins of accessory pericallosal arteries in man: case report. Surgical and Radiologic Anatomy, 2007, vol. 29, n. 4, p. 313-315. PMid:17487439. http://dx.doi.org/10.1007/ s00276-007-0213-5.

WAN-YIN, S., MING-HUA, L., BIN-XIAN, G., YONG-DONG, L. and HUA-QIAO, T. Azygous anterior cerebral artery and associated aneurysms: detection and identification using 3-dimensional time-offlight magnetic resonance angiography. Journal of Neuroimaging, 2014, vol. 24, n. 1, p. 18-22. PMid:23163794. http://dx.doi. org/10.1111/j.1552-6569.2012.00769.x.

Received February 11, 2016 Accepted February 23, 2017 